\title{
MATCHING METHOD FOR NODAL SOLUTIONS OF MULTI-POINT BOUNDARY VALUE PROBLEMS
}

\author{
QingKai Kong And Thomas E. St. George
}

Abstract. In this paper, we study the nonlinear boundary value problem consisting of the equation $y^{\prime \prime}+w(t) f(y)=0$ on $[a, b]$ and two multi-point boundary conditions. We establish the existence of various nodal solutions of this problem by matching the solutions of two boundary value problems, each of which involves one separated boundary condition and one multi-point boundary condition, at some point in $(a, b)$. We also obtain conditions for this problem not to have certain types of nodal solutions.

Mathematics subject classification (2010): 34B10, 34B15.

Keywords and phrases: nodal solutions, multi-point boundary value problems, Sturm-Liouville problems, eigenvalues, matching method.

\section{REFERENCES}

[1] Y. AN, Global structure of nodal solutions for second-order m-point boundary value problems with superlinear nonlinearities, Bound. Value Probl. (2011), Art. ID 715836, 12 pp.

[2] R. P. AgarWAL, I. KIgURADZE, On multi-point boundary value problems for linear ordinary differential equations with singularities, J. Math. Anal. Appl., 297 (2004), 131-151.

[3] J. Chamberlain, L. Kong, Q. Kong, Nodal solutions of boundary value problems with boundary conditions involving Riemann-Stieltjes integrals, Nonlinear Anal., 74 (2011), 2380-2387.

[4] J. Chamberlain, L. Kong, Q. Kong, Nodal solutions of nonlocal boundary value problems, Mathematical Modelling and Analysis, 14 (2009), 435-450.

[5] S. Clark, J. Henderson, Uniqueness implies existence and uniqueness criterion for nonlocal boundary value problems for third order differential equations, Proc. Amer. Math. Soc., 134 (2006), $3363-3372$.

[6] F. Genoud, B.P. Rynne, Second order, multi-point problems with variable coefficients, Nonlinear Anal., 74 (2011), 7269-7284.

[7] J. R. GRAEF, S. HEIDARKHANI, AND L. KONG, Infinitely many solutions for systems of multi-point boundary value equations, Topol. Methods Nonlinear Anal., to appear.

[8] J. R. Graef, B. YANG, Positive solutions to a multi-point higher order boundary value problem, J. Math. Anal. Appl., 316 (2006), 409-421.

[9] J. HENDERSON, Solutions of multipoint boundary value problems for second order equations, Dynam. Systems. Appl., 15 (2006), 111-117.

[10] J. HENDERSON, B. KARNA, C.C. TISDELL, Existence of solutions for three-point boundary value problems for second order equations, Proc. Amer. Math. Soc., 133 (2005), 1365-1369.

[11] L. Kong, Q. Kong, Existence of Nodal Solutions of Multi-Point Boundary Value Problem, Discrete and Continuous Dynamic Systems, Supplement, (2009), 457-465.

[12] L. Kong, Q. Kong, Nodal solutions of second order nonlinear boundary value problems, Math. Proc. Camb. Phil. Soc., 146 (2009), 747-763.

[13] L. Kong, Q. KonG, J.S.W. Wong, Nodal solutions of multi-point boundary value problems, Nonlinear Anal., 72 (2010), 382-389. 
[14] Q. KonG, Existence and nonexistence of solutions of second-order nonlinear boundary value problems, Nonlinear Anal., 66 (2007), 2635-2651.

[15] Q. Kong, H. Wu, A. ZettL, Dependence of the nth Sturm-Liouville eigenvalue on the problem, J. Differential Equations, 156 (1999), 328-354.

[16] Q. Kong, H. WU, A. ZETTL, Limits of Sturm-Liouville eigenvalues when the interval shrinks to an end point, Proc. Roy. Soc. Edinburgh, 138 A (2008), 323-338.

[17] Q. Kong, A. ZetTL, Eigenvalues of regular Sturm-Liouville problems, J. Differential Equations, 131 (1996), 1-19.

[18] M.K. KWONG, The shooting method and multiple solutions of two/multi-point BVPs of second-order $O D E$, Electron. J. Qual. Theory Differ. Equ. 6 (2006), 14 pp.

[19] M.K. Kwong And J.S.W. Wong, The Shooting Method and Non-homogeneous Multi-point BVPs of Second Order ODE, Boundary Value Problems, Vol. 2007, Art. ID 64012, 16pp.

[20] Y. LiU, D. O'REgAN, Multiplicity results using bifurcation techniques for a class of fourth-order m-point boundary value problems, Bound. Value Probl., 2009, Art. ID 970135, 20 pp.

[21] R. MA, Nodal solutions of second-order boundary value problems with superlinear or sublinear nonlinearities. Nonlinear Anal., 66 (2007), 950-961.

[22] R. MA, Nodal solutions for a second-order m-point boundary value problem, Czech. Math. J., 56(131) (2006), 1243-1263.

[23] R. MA, D. O'REgAn, Nodal solutions for second-order m-point boundary value problems with nonlinearities across several eigenvalues, Nonlinear Anal., 64 (2006), 1562-1577.

[24] R. Ma, B. Thompson, Multiplicity results for second-order two-point boundary value problems with superlinear or sublinear nonlinearities, J. Math. Anal. Appl., 303 (2005), 726-735.

[25] R. MA, B. Thompson, Nodal solutions for nonlinear eigenvalue problems, Nonlinear Anal., 59 (2004), 707-718.

[26] Y. NAITO, S. TANAKA, Sharp conditions for the existence of sign-changing solutions to equations involving the one-dimensional p-Laplacian, Nonlinear Anal., 69 (2008), 3070-3083.

[27] B. P. RYNne, Spectral properties and nodal solutions for second-order, m-point, boundary value problems, Nonlinear Anal., 67 (2007), 3318-3327.

[28] X. XU, Multiple sign-changing solutions for some m-point boundary-value problems, Electronic J. Diff. Eqns., No. 89 (2004), 1-14.

[29] X. XU, J. SUN, D. O'REgAN, Nodal solutions for m-point boundary value problems using bifurcation methods, Nonlinear Analysis, 68 (2008), 3034-3046.

[30] J.R.L. WEBB, K.Q. LAN, Eigenvalue criteria for existence of multiple positive solutions of nonlinear boundary value problems of local and nonlocal type, Topological Methods Nonlinear Analysis, 27 (2006), 91-115.

[31] A. ZettL, Sturm-Liouville theory, in: Mathematical Surveys and Monographs, vol. 121, American Mathematical Society, (2005). 